\title{
Pharmacists Perspective on Management of GBM
}

\author{
Lara Ellinger $^{1 *}$, Latha Radhakrishnan ${ }^{2}$ and Sandra Cuellar ${ }^{2}$ \\ ${ }^{1}$ Drug Information and Medication Safety, Northwestern Memorial Hospital, USA \\ ${ }^{2}$ Department of pharmacy, University of Illinois at Chicago College of Pharmacy, USA
}

Submission: October 06, 2016; Published: October 20, 2016

"Corresponding author: Lara Ellinger, Clinical Pharmacist, Drug Information and Medication Safety Northwestern Memorial Hospital, USA

\begin{abstract}
Management of patients with glioblastoma multiform requires the concerted efforts of multiple healthcare professionals, including pharmacists. Pharmacists across different practice settings may encounter patients being treated for glioblastoma multiforme. The oral chemotherapy temozolomide is a standard of care forglioblastoma multiforme, with dosing regimens and cycles that require dispensing considerations by the pharmacist as well as careful patient monitoring. Pharmacists should be able to direct the patient with glioblastoma multiforme to payment assistance for this drug as well. Bevacizumab is used to increase progression-free survival in recurrent glioblastoma multiforme, and pharmacists can also aid in the dosing and monitoring of this agent. Sequelae of glioblastoma multiforme include brain edema, seizures, venous thromboembolism, depression, and fatigue. Management of sequelae may include the use of corticosteroids, antiepileptic drugs, anticoagulants, and antidepressants, which can result in complex medication regimens. Toxicities and drug-drug interactions can be prevented and managed by pharmacists in both the outpatient and inpatient setting. Glioblastoma multiforme often leads to some degree of cognitive dysfunction, sorepeated education on medication regimens, adverse effects, and expectations of therapy are important for the patient and caregiver(s). Pharmacists are uniquely positioned to aid in the care of patient with glioblastoma multiforme.
\end{abstract}

Keywords: Glioblastoma multiforme glioblastoma; Brain tumor; Pharmacist; Temozolomide; Bevacizumab

Abbreviations: GBM: Glioblastoma Multiforme; MGMT: 06-Methylguanine Methyltransferase; IDH1: Isocitrate Dehydrogenase 1; RCTs: Randomized Controlled Trials; RT: Radiation Therapy; TMZ: Temozolomide; HR: Unadjusted Hazard Ratio; CI: Confidence Interval; NCCN: National Comprehensive Cancer Network; FDA: Food and Drug Administration; ANC: Absolute Neutrophil Count; CTC: Common Toxicity Criteria; PCP: Pneumocystis Cariniipneumonia; TMP/SMX: Trimethoprim/Sulfamethoxazole; ISMP: Institute for Safe Medication Practices; VEGF: Vascular Endothelial Growth Factor; BCNU: Biodegradable Carmustine; AEDs: Antiepileptic Drugs; VTE: Thromboembolism; ICH: Intracranial Hemorrhage; UFH: Unfractionated Heparin; SSRIs: Selective Serotonin Reuptake Inhibitors

\section{Introduction}

Glioblastoma multiforme (GBM), the most common malignant primary brain tumor in adults, is a devastating malignancy with a rapid clinical course [1]. The disease course and psychological impact to patients and their families requires a multidisciplinary approach to treatment. Multiple review articles have stressed the importance of the roles of neurosurgeons, neurooncologists, radiologists, nurses, rehabilitation therapists, as well as psychological support teams and general practitioners, but the role of the pharmacist in the management of GBM has yet to be delineated in the published literature [1-3]. Issues pertinent to pharmacists in the management of GBM include chemotherapy, drug interactions, pharmacologic management of sequelae, and supportive care. The objective of this article is to provide an overview of the treatment of GBM, with a focus on the pharmacologic agent's temozolomide and bevacizumab, as well as highlight the areas where pharmacists can be a part of the GBM management team.
Glioblastoma multiforme is classified as a grade IV malignant cancer originating from astrocytic glial cells of the brain [4]. Glioblastoma multiforme can occur as either primary (de novo) or secondary (a lower grade glioma that progresses to GBM), with over $90 \%$ occurring as primary [1,2]. Overall, GBM accounts for $50 \%$ of glial cell tumors, with an incidence rate of 3.2 per 100,000 person-years [4,5]. Glioblastoma multiforme occurs more commonly in persons between the ages of 45 and 65 years, and affects whites at an incidence twice that of blacks [6]. The presentation of GBM varies, with common signs and symptoms of headaches, seizures, memory loss, and changes in behavior [4]. The highly aggressive nature of GBM makes treatment difficult, with an expected 5-year survival rate of $<5 \%[5,6]$. Only one third of patients with GBM are expected to survive 1 year after diagnosis [7]. Important prognostic factors include histologic diagnosis, age, and performance status, as measured by Karnofsky Performance Scale (KPS) [5,7]. 


\section{Cancer Therapy \& Oncology International Journal}

Also, recent understanding of molecular genetics variables suggests that 06-methylguanine methyltransferase (MGMT) promoter methylation and isocitrate dehydrogenase 1 (IDH1) mutationshave prognostic and therapeutic response implications as well [8]. Despite advances in research and pharmacologic treatment methods, the median survival of 9 to 14 months after diagnosis is similar to what it was 20 years ago [5]. Unfortunately, GBM recurs in nearly $100 \%$ of patients, and is more difficult to treat [2]. Recently, literature has been published offering additional therapeutic options for recurrent disease.

\section{Treatment overview - non-pharmacologic}

Surgery and radiation: The cornerstone of treatment of GBM is surgery, despite its lack of validation in phase III randomized controlled trials (RCTs) [2]. Tumor resection allows for an accurate diagnosis, a decrease in tumor mass (which alleviates associated symptoms), and a more favorable response to postsurgical radiation therapy (RT) [9]. Surgery only increases survival when it achieves $>98 \%$ resection of the tumor. However, this is difficult due to the infiltrative nature of the tumor. If submaximal tumor reduction occurs, residual tumor may behave more aggressively and result in worsening edema and mass tumor effect [2].

Postsurgical RT, the first postsurgical adjuvant therapy used historically, is still a part of the standard of care today [2]. In the 1960s to 1970s RCTs consistently showed postsurgical RT to be efficacious in the treatment of GBM, extending survival from 4 to 6 months to 10 to 11 months. Variations of RT regimens as well as RT with radiosensitizers have been studied, but no improvements in survival have been made. Today, localized RT is initiated at least 2 weeks after surgery and administered as fractionated external beam RT at a 60 Gy dosein 30 fractions over 6 weeks [7,9]. Abbreviated courses may be used in those with poor performance statuses (KPS $<60$ ) or in elderly patients ( $\geq 65$ years) $[2,7,9]$.

\section{Treatment overview - pharmacologic}

Temozolomide - evidence: Temozolomide (TMZ) is available orally as well as a powder for injection [10]. It is an alkylating agent indicated for adjuvant treatment for newly diagnosed GBM, and is now the standard for those who have a good performance status (KPS $\geq 60$ ) $[7,10]$. The methylation status of the DNA repair enzyme, MGMT, is thought to be a predictor of response to TMZ [7,11]. Overexpression of the MGMT protein confers resistance to TMZ, and methylation of the MGMT gene can inactivate the production of the MGMT protein. Those patients with a methylated MGMT promoter region are likely to respond to therapy. Obtaining MGMT methylation status before treatment is not currently a standard of care because there are no strategies to overcome TMZ resistance. Treatment with TMZ is administered regardless of MGMT status.

A key trial included 573 patients with glioblastoma, and randomized them to treatment with postoperative RT and concomitant TMZ, followed by 6cycles of adjuvant TMZ, or to RT alone given 5 days weekly for 6 weeks [12]. The results were published by Stupp et al in 2005, showing that TMZ combined with RT reduced the risk of death by $37 \%$ compared to RT alone [unadjusted hazard ratio (HR), 0.63, 95\% confidence interval (CI) 0.52 to $0.75 ; \mathrm{P}<0.001]$. After 28 months the median survival was 14.6 months for TMZ combined with RT, and 12.1 months with RT alone. The 2-year survival rate was $26.5 \%$ in the combination group and $10.4 \%$ in the RT alone group. The main adverse effects of TMZ were hematologic, with $16 \%$ of patients in the combination group experiencing grades 3 or 4 hematologic adverse effects (leukopenia, neutropenia, thrombocytopenia, and anemia).

No patients in the RT alone group experienced grades 3 or 4 hematologic adverse effects. A later analysis of the trial revealed that during the 5-year follow-up period, approximately $10 \%$ of patients in the combination group were still alive, compared to $2 \%$ in the RT alone group [13]. The regimen used in the trial is described in (Table 1), and has since been referred to as the "Stupp regimen." Unfortunately, given the trial design, it is unclear which part of the Stupp regimen - concomitant TMZ, adjuvant TMZ, or the combination of both - is responsible for the benefits that are seen. A myriad of alternative dosing regimens and schedules of TMZ have also been studied, but the National Comprehensive Cancer Network (NCCN) guidelines still recommend the use of the regimen used in the study by Stupp and colleagues $[7,12]$.

\section{Temozolomide - implications for the pharmacist:}

Table 1: Temozolomidedosing regimens for glioblastoma multiforme [12,14-17].

\begin{tabular}{|c|c|c|c|c|}
\hline Study & Concomitant Dose (with Radiation Therapy) & Adjuvant Dose & Schedule & \# of Cycles \\
\hline \multicolumn{5}{|c|}{ Newly diagnosed GBM } \\
\hline $\begin{array}{l}\text { Stupp et al, } 2005 \\
\text { "Stupp regimen" }\end{array}$ & $75 \mathrm{mg} / \mathrm{m}^{2}$ daily for 42 days & $\begin{array}{l}\text { Cycle 1: } 150 \mathrm{mg} / \mathrm{m}^{2} \\
\text { Cycle 2: } 200 \mathrm{mg} / \mathrm{m}^{2}\end{array}$ & $\begin{array}{c}5 \text { days, every } 28 \\
\text { days }\end{array}$ & 6 \\
\hline $\begin{array}{l}\text { Gilbert 2011a } \\
\text { (RTOG 0525) } \\
\text { "Dose dense" }\end{array}$ & $75 \mathrm{mg} / \mathrm{m}^{2}$ daily for 42 days & 75 to $100 \mathrm{mg} / \mathrm{m}^{2}$ & $\begin{array}{l}21 \text { days, every } \\
28 \text { days }\end{array}$ & $6-12$ \\
\hline \multicolumn{5}{|c|}{ Recurrent GBM } \\
\hline $\begin{array}{l}\text { Perry } 2008 \\
\text { "Rescue" }\end{array}$ & $\mathrm{n} / \mathrm{a}$ & $50 \mathrm{mg} / \mathrm{m}^{2}$ & Daily & $\begin{array}{c}\text { Until } \\
\text { progression }\end{array}$ \\
\hline
\end{tabular}




\section{Cancer Therapy \& Oncology International Journal}

\begin{tabular}{|c|c|c|c|c|}
\hline $\begin{array}{c}\text { Wick } 2007 \\
\text { "1 week on 1 week off" }\end{array}$ & n/a & $150 \mathrm{mg} / \mathrm{m}^{2}$ & $\begin{array}{c}\text { Days 1-7 and } \\
15-21 \text { of 28 } \\
\text { days }\end{array}$ & $\begin{array}{c}\text { Maximum 12 } \\
\text { Tolcher } 2003\end{array}$ \\
"Protracted regimen" & n/a & 50 to $150 \mathrm{mg} / \mathrm{m}^{2}$ & $\begin{array}{c}\text { Days 1-21 of 28 } \\
\text { days }\end{array}$ & $\begin{array}{c}\text { Until } \\
\text { progression }\end{array}$ \\
\hline
\end{tabular}

aLikely will not be commonly seen in clinical practice as the study did not demonstrate increased efficacy of a dose-dense regimen for this patient population.

Dosing regimens: The standard dosing scheme and alternative dosing schemes for TMZ can be viewed in (Table 1). Although TMZ does not have US Food and Drug Administration (FDA) approval for use in recurrent GBM, smaller studies of dose-dense regimens have shown some efficacy with its use for this indication [14-16]. The theory behind dose-dense TMZ regimens is that they more effectively deplete MGMT, so that the affected DNA cannot be repaired, allowing the tumor cells to be more susceptible to the antitumor activity of the alkylating agent $[11,17]$. It is thought that patients with GBM who are refractory to initial therapy have an unmethylated MGMT gene, resulting in overexpression of MGMT, and could therefore benefit from dosedense TMZ regimens.

Toxicities and dose reductions: The most common adverse effects of TMZ during the concomitant phase with RT include

thrombocytopenia, nausea, vomiting, anorexia, and constipation $[10,12]$. At any point during therapy, common adverse effects may include alopecia, nausea, vomiting, anorexia, headache, and constipation. Temozolomide is classified as moderately to highly emetogenic when doses exceed $75 \mathrm{mg} / \mathrm{m}^{2} /$ day, andit is low to minimally emetogenic when doses are $<75 \mathrm{mg} / \mathrm{m}^{2} /$ day [18]. When combined with RT at a dose of $\leq 75 \mathrm{mg} / \mathrm{m}^{2}$, it is considered moderately emetogenic. For emesis prophylaxis, the NCCN Antiemesis Guidelines recommend an oral 5-HT3 antagonist with or without lorazepam and with or without an acid reducer (such as a histamine-2 receptor antagonist or proton pump inhibitor). When TMZ is given at doses rendering it lowly emetogenic, metoclopramide or prochlorperazine may be used. Temozolomide may be taken on an empty stomach should nausea/vomiting occur; some find bedtime is most convenient [10]. (Table 2) reviews antiemesis options for temozolomide.

Table 2: Antiemesis options for temozolomide [18].

\begin{tabular}{|c|c|}
\hline Antiemetic & Dose \\
\hline \multicolumn{2}{|c|}{ Moderate to High Emetogenicity (TMZ dose $>75 \mathrm{mg} / \mathrm{m}^{2} /$ day) ${ }^{a}$} \\
\hline Granisetron & $\begin{array}{c}1 \mathrm{mg} \text { po bid } \\
\text { or } \\
2 \mathrm{mg} \text { po daily }\end{array}$ \\
\hline Ondansetron & 16 to $24 \mathrm{mg}$ po daily \\
\hline \multicolumn{2}{|c|}{ Low to Minimal Emetogenicity (TMZ dose $<75 \mathrm{mg} / \mathrm{m} 2 /$ day)a } \\
\hline Metoclopramide & $\begin{array}{c}10 \text { to } 40 \mathrm{mg} \text { po prior to TMZ } \\
\text { then } \\
\text { q } 4 \text { to } 6 \mathrm{hrs} \text { prn }\end{array}$ \\
\hline Prochlorperazine & $\begin{array}{c}10 \mathrm{mg} \text { po prior to TMZ } \\
\text { then } \\
\text { q } 4 \text { to } 6 \mathrm{hrs} \text { prn }\end{array}$ \\
\hline \multicolumn{2}{|c|}{ Additional Optional Agents } \\
\hline Lorazepam & 0.5 to $2 \mathrm{mg}$ po $\mathrm{q} 4$ to $6 \mathrm{hrs}$ prn \\
\hline $\mathrm{H} 2$ antagonist or proton pump inhibitor & Varying agents and doses \\
\hline
\end{tabular}

TMZ: Temozolomide

aEmetogenic potential of TMZ may change when used with other emetogenic agents or in combination with radiotherapy.

Hematologic toxicities are a concern with TMZ and can occur early in treatment [10]. Prior to dispensing TMZ, the pharmacist should ensure the patient meets the following criteria: absolute neutrophil count $(\mathrm{ANC})>1.5 \times 10^{9} / \mathrm{L}$, platelet count $>100 \times$ $10^{9} / \mathrm{L}$, and common toxicity criteria (CTC) nonhematological toxicity < grade 1 (except for alopecia, nausea, and vomiting). Complete blood counts should be obtained each week. The doselimiting toxicity for TMZ is myelosuppression (neutropenia and thrombocytopenia) with grade 3 or 4 neutrophil abnormalities occurring in approximately $8 \%$ of patients and grade 3 or 4 
platelet abnormalities in $14 \%$ of patients. Some toxicity may require TMZ dose reduction/discontinuation, especially during the concomitant phase with RT (Table 3). Dose reductions based on hematologic toxicities during the maintenance phase can be seen in (Tables $4 \& 5$ ). A recent review of FDA MedWatch data from 1997 to 2008 found 76 cases of aplastic anemia or aplasia were reported in 3490 patients taking TMZ [19]. These reports were from patients on TMZ for any indication, not just GBM. Patients are most at risk for hematologic toxicities when receiving concomitant $\mathrm{RT}$ and/or other myelosuppressive chemotherapy.

Table 3: Temozolomide dosing interruption or discontinuation during concomitant radiotherapy and temozolomide [10].

\begin{tabular}{|c|c|c|}
\multicolumn{1}{|c|}{ Toxicity } & \multicolumn{1}{|c|}{ TMZ Interruption } & $\begin{array}{c}\text { TMZ } \\
\text { discontinuation }\end{array}$ \\
\hline $\begin{array}{c}\text { Absolute neutrophil } \\
\text { count }\end{array}$ & $\begin{array}{c}>0.5 \text { and }<1.5 \mathrm{x} \\
10^{9} / \mathrm{L}\end{array}$ & $<0.5 \times 10^{9} / \mathrm{L}$ \\
\hline Platelet count & $\begin{array}{c}>10 \text { and }<100 \mathrm{x} \\
10^{9} / \mathrm{L}\end{array}$ & $<10 \times 10^{9} / \mathrm{L}$ \\
\hline $\begin{array}{c}\text { CTC nonhematological } \\
\text { toxicity (except for } \\
\text { alopecia, nausea, } \\
\text { vomiting) }\end{array}$ & CTC grade 2 & CTC grade 3 or 4 \\
\hline
\end{tabular}

TMZ: Temozolomide; CTC: Common Toxicity Criteria

aTreatment with concomitant TMZ could be continued when all of the following conditions were met: absolute neutrophil count 1.5× 109/L; platelet count ${ }^{3} 100 \times 109 / \mathrm{L}$; CTC non-hematological toxicity Grade 1 (except for alopecia, nausea, vomiting).

Table 4: Temozolomide dose levels for maintenance treatment [10].

\begin{tabular}{|c|c|c|}
\hline Dose level & Dose $\left(\mathrm{mg} / \mathrm{m}^{2} /\right.$ day $)$ & Remarks \\
\hline-1 & 100 & $\begin{array}{l}\text { Reduction for prior } \\
\text { toxicity }\end{array}$ \\
\hline 0 & 150 & Dose during cycle 1 \\
\hline 1 & 200 & $\begin{array}{c}\text { Dose during cycles } \\
2-6 \text { in absence of } \\
\text { toxicity }\end{array}$ \\
\hline
\end{tabular}

Table 5: Nonhematological toxicity (except for alopecia, nausea, vomiting) recurs after dose reduction.

\begin{tabular}{|c|c|c|}
\hline Toxicity & $\begin{array}{c}\text { Reduce TMZ by } \mathbf{1} \\
\text { dose levela }\end{array}$ & Discontinue TMZ \\
\hline $\begin{array}{c}\text { Absolute neutrophil } \\
\text { count }\end{array}$ & $<1.0 \times 10^{9} / \mathrm{L}$ & See footnote $^{\mathrm{b}}$ \\
\hline Platelet count & $<50 \times 10^{9} / \mathrm{L}$ & See footnote $^{\mathrm{b}}$ \\
\hline $\begin{array}{c}\text { CTC Nonhematological } \\
\text { Toxicity } \\
\text { (except for alopecia, } \\
\text { nausea, vomiting) }\end{array}$ & CTC grade 3 & CTC grade 4 \\
\hline Toxicity & $\begin{array}{c}\text { Reduce TMZ by } 1 \\
\text { dose level }\end{array}$ & Discontinue TMZ \\
\hline
\end{tabular}

TMZ: Temozolomide; CTC: Common Toxicity Criteria.

aTMZ dose levels are listed in (Table 4)

${ }^{\mathrm{b}} \mathrm{TMZ}$ is to be discontinued if dose reduction to $<100 \mathrm{mg} / \mathrm{m}^{2}$ is required or if the same Grade 3
Given the severe lymphocytopenia that patients experience during the concomitant phase when TMZ is combined with RT, Pneumocystis carinii pneumonia (PCP) prophylaxis needs to be administered during concomitant therapy [10]. During concomitant therapy, prophylaxis for PCP should be continued regardless of ANC, and continued after the concomitant phase until lymphocytopenia is resolved or no worse than CTC grade 1. Continuation of PCP prophylaxis should be considered in the maintenance phase if the patient is also receiving steroids. The pharmacist should collaborate with the patient's care team to discuss when PCP prophylaxis is no longer necessary. The NCCN listsoral trimethoprim/sulfamethoxazole (TMP/SMX) as the preferred agent for PCP prophylaxis [20]. It can be administered as single strength or double strength daily or double strength 3 times per week. Alternative agents for PCP prophylaxis in patients who are allergic or intolerant to TMP/SMX include dapsone, inhaled pentamidine, oratovaquone.

Dispensing: Since TMZ is supplied as 6 different capsule strengths, pharmacists will often have to dispense varying quantities of different strengths in order to obtain the correct dosage for each patient [10]. The package insert has a chart that suggests capsule combinations based on a patient's daily dose. Each strength should be dispensed in a separate bottle, or the original container, and labeled with the number of capsules that should be taken from each container each day. An error reported to the Institute for Safe Medication Practices (ISMP) involved a pharmacist who misinterpreted the quantity on the temozolomide bottle as the strength [21]. The temozolomide script was written for a dose of $60 \mathrm{mg}$ ( 3 of the $20 \mathrm{mg}$ capsules for each dose), and the pharmacist inadvertently filled the prescription with $100 \mathrm{mg}$ capsules after mistaking the quantity of 20 listed on the bottle for the strength. If taken as filled, the patient could have experienced severe hematologic toxicities [21]. The ISMP suggests highlighting the strength of the TMZ prescription to draw attention to it.

Pharmacists should also counsel patients on the directions and taking it at the same time every day, and confirm understanding with the patient. Impaired cognitive function may be a result of the disease, so patients may struggle with reading or comprehending instructions. The use of calendars and pillboxes may be helpful as well. Pharmacists should also be cognizant that dosages will likely change depending on which cycle patients are in, whether they are receiving concomitant RT, and/or if they experience toxicities. The pharmacist will need to order TMZ based on if the patient is following a 5-day or 42day regimen, or perhaps a continuous or dose-dense regimen. It is important that the pharmacist document (or has access to documentation of) the patient's ANC and platelet values for that cycle. Refills should not be dispensed until hematologic criteria are met, as dictated by the prescribing physician and the TMZ package insert. 


\section{Cancer Therapy \& Oncology International Journal}

Some patients with GBM may have swallowing difficulties or dysphagia, making it difficult to ingest the TMZ capsules. The capsules are on the ISMP list of medications that should not be crushed or opened, due to the slow-release formulation and safety issues of inhalation and/or skin exposure [22]. Swallowing difficulties are especially concerning to patients when combinations of different strengths of capsules must be taken in order to achieve the prescribed daily dose [10]. As such, patients can have their pharmacist compound a TMZ solution following the recipe found in (Table 6) [23]. Temozolomide is also available as an injection [10]. This may be especially useful for patients with refractory nausea due to tumor progression, dysphagia due to a brainstem tumor, or younger patients reluctant to swallow capsules [24]. When infused over 90 minutes, the intravenous form of temozolomide displays similar pharmacokinetics as the oral formulation, which is also $100 \%$ bioavailable.

Table 6: Temozolomide $10 \mathrm{mg} / \mathrm{mL}$ oral liquid [23].

\begin{tabular}{|c|c|}
\hline Ingredients & Amount \\
\hline Temozolomide & $1 \mathrm{~g}$ \\
\hline Povidone K-30a & $500 \mathrm{mg}$ \\
\hline Citric acid, anhydrous & $25 \mathrm{mg}$ \\
\hline Purified water & $1.5 \mathrm{~mL}$ \\
\hline Ora-Plus & $50 \mathrm{~mL}$ \\
\hline Ora-sweet or Ora-Sweet SF & QS $100 \mathrm{~mL}$ \\
\hline
\end{tabular}

aThis product is often available for order through pharmacy wholesalers.

1. Calculate the required quantity of each ingredient for the total amount to be prepared.

2. Weigh and/or measure each ingredient accurately.

3. Empty the contents of the temozolomide capsules into a suitable mortar.

4. Add the povidone $\mathrm{K}-30$ to the mortar and blend the powders well.

5. Dissolve the citric acid in the purified water and add to the powder mixture.

6. Add a small amount of Ora-Plus to the mixture and mix well.

7. Add the remainder of the Ora-Plus geometrically and mix well.

8. Transfer to a calibrated container.

9. Rinse the mortar with either the Ora-Sweet or Ora-Sweet $\mathrm{SF}$, add to the calibrated container, and mix well.

10. Repeat until the final volume has been obtained.

11. Mix the solution well.

12. Package in a tight, light-resistant container.

13. Label with "keep out of reach of children," and "use only as directed."

14. Expiration: 60 days from time of preparation if stored in a refrigerator.

Payment assistance: The pharmacist (both community and ambulatory care) can also play an important role in helping patients and their families obtain financial assistance with paying for TMZ treatment. The cost of TMZ is thousands of dollars per month, regardless of use of brand or generic. Pharmacists can help patients enroll in financial assistance programs by the manufacturer. Merck \& Company, Inc. offers the ACT Program and the Co-Pay Assistance Program, both of which provide financial assistance to patients whose income is below a certain level. The ACT Program is for those who do not have prescription coverage and the Co-Pay Assistance Program is for those with private insurance who cannot afford their co-pay [25]. The website rxassist.org provides an overview of each program and links to application forms. If pharmacists receive rejection messages from a patient's insurance company or the co-pay is unaffordable to the patient, the pharmacist should notify the prescriber immediately so that the necessary steps can be taken to avoid a delay in therapy. Recently, generic formulations have been made available; however, drug acquisition can still be a challenge.

\section{Bevacizumab- evidence}

The tumor characterization of glioblastomas such as intense vascular proliferation and increased expression of angiogenic factors such as vascular endothelial growth factor (VEGF) have made VEGF an attractive therapeutic target for management of glioblastomas [26]. Bevacizumab is a humanized monoclonal antibody designed to target VEGF and studies have demonstrated improved progression free survival in recurrent GBM [27]. In 2009 , bevacizumab received accelerated approval from the FDA for use as monotherapy in progressive glioblastoma, based on improved radiologic response rates observed with bevacizumab monotherapy in 2 single-arm/noncomparative phase II trials compared with historical data $[26,28]$.

The first phase II trial included 167 patients with recurrent glioblastoma who were randomly assigned to receive bevacizumab $10 \mathrm{mg} / \mathrm{kg}$ alone or in combination with irinotecan $340 \mathrm{mg} / \mathrm{m}^{2}$ or $125 \mathrm{mg} / \mathrm{m}^{2}$ (with or without concomitant enzymeinducing antiepileptic drugs) once every 2 weeks [26]. The results of the trial demonstrated an estimated 6-month progression free survival rate of $42.6 \%$ in the bevacizumab monotherapy arm versus $50.3 \%$ in the combination arm. The median overall survival times were 9.2 months and 8.7 months, respectively. In terms of safety, approximately $46.4 \%$ of patients experienced $\geq$ grade 3 adverse events in the bevacizumab arm versus $65.8 \%$ in the combination arm. The most common toxicities reported in the monotherapy arm included hypertension and convulsion versus convulsion, neutropenia, and fatigue in the combination arm.

The second trial the FDA based its accelerated approval on was a phase II trial with 48 heavily pretreated patients who received single agent bevacizumab $10 \mathrm{mg} / \mathrm{kg}$ every 2 weeks and after tumor progression irinotecan was added similar to the previous study [28]. Median progression free survival was 16 weeks and median 6 month overall survival was $57 \%$. The most common adverse events reported included 


\section{Cancer Therapy \& Oncology International Journal}

thromboembolic events, hypertension, hypophosphatemia, and thrombocytopenia. The results of these two studies demonstrate the activity of bevacizumab in GBM with acceptable toxicity profile and also suggests the limited benefit with the combination with irinotecan $[26,28]$.

However, combining bevacizumab with chemotherapy is not a foregone conclusion. A Dutch study explored combining bevacizumab with lomustine [29]. The BELOB study trial randomly assigned patients to bevacizumab, lomustine, or bevacizumab plus lomustine at first recurrence of GBM Progression free survival at 6 months was $41 \%$ with the combination of bevacizumab and lomustine versus $18 \%$ with bevacizumab alone and $11 \%$ withlomustinealone. The overall survival at 9 months was $59 \%$ in the combination group versus $38 \%$ and $43 \%$ for the bevacizumab and lomustine-alone groups, respectively. Recently, a study was published evaluating the addition of bevacizumab to radiotherapy plus temozolomide in newly diagnosed glioblastoma [30]. In this study, the addition of bevacizumab did not improve patient survival. Bevacizumab's role in the management of GBM continues to evolve in the recurrent setting and data is not matured in the newly diagnosed setting.

\section{Bevacizumab - implications for the pharmacist:}

I. Dosin: Bevacizumab dosing in the aforementioned clinical trials is $10 \mathrm{mg} / \mathrm{kg}$ every 2 weeks. Wong, et al performed a meta-analysis of 15 studies involving over 500 patients treated with bevacizumab for recurrent GBM [31]. The meta-analysis found no difference in bevacizumab doseresponse between $5 \mathrm{mg} / \mathrm{kg}$ and 10 to $15 \mathrm{mg} / \mathrm{kg}$. However, a prospective analysis needs to be conducted to confirm the findings.

II. Toxicities: In general, bevacizumab is well tolerated in patients with recurrent GBM, and the toxicities observed in clinical trials are comparable to those seen in other cancers [27]. Low-grade bleeding, hypertension, impaired wound healing, and proteinuria are the most common adverse events attributable to bevacizumab in recurrent GBM studies. Blood pressure readings should be documented at baseline and prior to bevacizumab administration. Adverse events such as life-threatening intracranial bleeding have occurred in a $\leq 3 \%$ of patients and prevalence of thromboembolism is approximately $1.6 \%$ to $12.5 \%$ [32]. No special precautions or additional monitoring are necessary when treating GBM patients with bevacizumab.

III. Other treatment options: Another initial treatment option for GBM is local administration of chemotherapy [7]. The biodegradable carmustine (BCNU) wafer is implanted during surgery, and may be administered regardless of performance status. The wafers do not result in systemic absorption of the nitrosoureacarmustine, thus minimizing systemic side effects. Irinotecan has been studied in combination with bevacizumab for recurrent glioblastoma multiforme [26,28,33]. Parameters such as complete blood cell count with differential and liver function tests should be monitored at baseline and regularly prior to irinotecan administration. As irinotecan is metabolized hepatically, caution should be taken when administering with enzymeinducing antiepileptic drugs (AEDs) such as phenytoin. Patients receiving concurrent irinotecan and phenytoin will have reduced exposure to irinotecan and its active metabolite, SN-38 [34]. To avoid decreased chemotherapeutic efficacy, irinotecan doses are significantly increased if patients are on concomitant enzyme-inducing AEDs [33].

\section{Sequelae and treatment-related adverse effects}

I. Brain edema: Dexamethasone is commonly used for the management of brain edema in patients with GBM or with other cancers that have metastasized to the brain $[1,35]$. Brain edema associated with GBM is usually of the vasogenic extracellular type, which is plasma leakage into the brain parenchyma due to increased brain capillary permeability and a pressure gradient. Tight junctions on endothelial cells of the blood-brain barrier can become dysfunctional, leading to capillary permeability. Vascular endothelial growth factor has been implicated in this process, as it mediates proteins involved in tight junction formation. Corticosteroids, such as dexamethasone, reduce expression of VEGF and therefore reduce formation of cerebral edema. Other mechanisms for edema reduction by corticosteroids have also been proposed. Overall, reductions in capillary permeability can be seen as soon as 1 hour after corticosteroid administration. With dexamethasone, full effect is reached within 24 to 72 hours of administration.

Management of brain edema with corticosteroids implications for the pharmacist: Patients with GBM often receive dexamethasone for cerebral edema at diagnosis, postoperatively, at the time of radiation, and if the tumor progresses $[1,35,36]$. Management of edema can help alleviate associated headache, cognitive deficits, nausea/vomiting, and seizures. The dose of dexamethasone can range from $4 \mathrm{mg}$ to $100 \mathrm{mg}$ daily, with typical doses in the range of $12 \mathrm{mg}$ to $16 \mathrm{mg}$ daily. It can also be administered intravenously. One study found similar improvement in neurologic function with a $4 \mathrm{mg}$ dose compared to $16 \mathrm{mg}$, but a higher incidence of muscle weakness and cushingoid faces were seen with the $16 \mathrm{mg}$ dose [37]. Other adverse effects that pharmacists should be able to counsel patients on include hyperglycemia, drug interactions (Table 7), and the possibility of corticosteroid-induced ulcers [35]. It may be advisable for patients to receive concomitant histamine- 2 receptor antagonists or a proton pump inhibitor as ulcer prevention. Infection and psychiatric complications are also risks. Upon discontinuation, corticosteroids should be tapered over 2 to 3 weeks. It is recommended that this be achieved by decreasing the dose by $50 \%$ every 4 days. Patients who have a poorer performance status may be tapered by $25 \%$ every 8 days to avoid deterioration associated with rapid tapering. 


\section{Cancer Therapy \& Oncology International Journal}

Table 7: Interactions between treatment agents for glioblastoma multiforme and agents used in the management of its sequelae [34,45,53,54].

\begin{tabular}{|c|c|c|c|}
\hline Drug Interaction & & Interacting agent & Interacting agent \\
\hline $\begin{array}{l}\text { Agents commonly used } \\
\text { for treatment of GBM and } \\
\text { management of sequelae }\end{array}$ & Interacting agent & & \\
\hline Bevacizumab & Warfarin & Risk of bleeding may be increased & $\begin{array}{l}\text { Monitor INR and educate patient } \\
\text { to seek help if new headache or } \\
\text { neurologic changes occur, which } \\
\text { may be signs of ICH }\end{array}$ \\
\hline \multirow{4}{*}{ Dexamethasone } & Carbamazepine & $\begin{array}{l}\text { Effects of dexamethasone may be } \\
\text { decreased }\end{array}$ & $\begin{array}{l}\text { Dexamethasone dose may need to } \\
\text { be increased }\end{array}$ \\
\hline & & $\begin{array}{l}\text { Effects of dexamethasone may be } \\
\text { decreased }\end{array}$ & \\
\hline & Phenytoin & $\begin{array}{c}\text { Effects of phenytoin may be } \\
\text { decreased }\end{array}$ & $\begin{array}{l}\text { Phenytoin levels may be difficult } \\
\text { to predict; careful monitoring and } \\
\text { dose adjustment will likely be } \\
\text { necessary }\end{array}$ \\
\hline & Warfarin & $\begin{array}{l}\text { Unpredictable effects on } \\
\text { coagulation; both bleeding and } \\
\text { thromboembolism have been } \\
\text { reported with concomitant use of } \\
\text { agents }\end{array}$ & $\begin{array}{l}\text { Monitor INR and adjust warfarin } \\
\text { dose accordingly }\end{array}$ \\
\hline \multirow{2}{*}{ Irinotecan } & Phenytoin & $\begin{array}{l}\text { Reduction in exposure to } \\
\text { irinotecan }\end{array}$ & $\begin{array}{l}\text { Consider substitution of a non- } \\
\text { enzyme inducing AED } 2 \text { weeks } \\
\text { prior to initiation of irinotecan }\end{array}$ \\
\hline & Carbamazepine & $\begin{array}{l}\text { Reduction in exposure to } \\
\text { irinotecan }\end{array}$ & $\begin{array}{l}\text { Consider substitution of a non- } \\
\text { enzyme inducing AED } 2 \text { weeks } \\
\text { prior to initiation of irinotecan }\end{array}$ \\
\hline Sulfamethoxazole/trimethoprim & Phenytoin & $\begin{array}{l}\text { Increased phenytoin exposure } \\
\text { resulting in phenytoin toxicity }\end{array}$ & $\begin{array}{l}\text { Avoid use of sulfamethoxazole/ } \\
\text { trimethoprim; inhaled } \\
\text { pentamidine should be } \\
\text { administered for Pneumocystis } \\
\text { jirovecii pneumonia }\end{array}$ \\
\hline Temozolomide & Warfarin & Risk of bleeding may be increased & $\begin{array}{l}\text { Monitor INR and educate patient } \\
\text { to seek help if new headache or } \\
\text { neurologic changes occur, which } \\
\text { may be signs of ICH }\end{array}$ \\
\hline
\end{tabular}

AED: Antiepileptic Drug; ICH: Intracranial Hemorrhage; INR: International Normalized Ratio

Seizures: At the time of GBM diagnosis, up to $40 \%$ of patients have experienced seizures [1,38]. Seizures may often be the presenting symptom of GBM. Because edema and tumor size contribute to seizure development, a reduction in tumor size and a decrease in edema may partially or fully control seizures [5]. However, a majority of patients will still require treatment with AEDs during their disease course. Meta-analyses and reviews have found that seizure prophylaxis with AEDs is ineffective, even when patients with subtherapeutic AED levels were excluded [1,38]. Also, adverse effects of AEDs are documented to be $20 \%$ to $40 \%$ higher in patients with brain tumors as compared to those without brain tumors. Thus, use of AEDs is not warranted when there are likely no benefits and only risks involved. In patients with brain tumors who have not yet experienced seizures, The American Academy of Neurology does not recommend prophylactic AED use due to lack of benefit and the propensity of these medications to interact with chemotherapy and corticosteroids [38].
For patients with GBM who do experience seizures, standard epilepsy therapy applies $[1,39,40]$. Monotherapy is often used given its lower incidence of adverse effects and better compliance rates. There is disagreement on preferred therapy/regimens for these patients, as little evidence exists to support the use of one agent or combination of agents over another. Seizure control, adverse effects, and drug interactions are major factors that dictate choice of therapy. Many of the AEDs are well-known for their induction of hepatic cytochrome P-450 enzymes, especially 3A4 [5]. This has implications for the patient with GBM since medications they commonly take, including some chemotherapy, steroids, antibiotics, warfarin, and antidepressants, are metabolized by and/or also induce or inhibit these hepatic enzymes as well [39]. (Table 7) lists drug interactions that may occur between chemotherapy for GBM and agents (both AED and non-AED) used for management of its sequelae.

Valproic acid and levetiracetamare agents commonly used as first-line monotherapy for seizures in patients with GBM 


\section{Cancer Therapy \& Oncology International Journal}

[40]. A retrospective analysis of the patients enrolled in the trial by Stupp, et al, analyzed the use of AEDs with radiation and temozolomide, adjusting for known prognostic variables [41]. While overall survival did not differ between patients taking AEDs and those who were not, there appeared to be a survival advantage from the chemoradiation (temozolomide/ radiation) in patients taking valproic acid as compared to those taking enzyme-inducing AEDs or no AEDs. The correlating median survival times were 17.3 months, 14.4 months, and 14.0 months, respectively. It has been hypothesized that valproic acid enhances antitumor effects of chemoradiation through inhibition of histone deacetylase, inducing autophagy $[42,43]$.

Regardless of possible antitumor effects, valproic acid has shown to be effective alone and in combination with other AEDs for seizures in some patients with brain tumors, including GBM. Van Breemen and colleagues found valproic acid alone and in combination with levetiracetam resulted in a $79.3 \%$ and $81.5 \%$ seizure response rate, respectively [43]. Considerations for use of valproic acid include thrombocytopenia, drug interactions due to inhibition of CYP2C9, the need for add-on agents for further seizure control in some patients, and therapeutic drug monitoring $[40,44]$. Levetiracetam may also be effective monotherapy, with the benefits of good tolerance, lack of drug interactions and no need for therapeutic drug monitoring [40]. While drug interactions may be avoided with levetiracetam, dose adjustments are required for renal dysfunction, whereas this is not the case with valproic acid $[34,40]$.

Phenytoin is another AED commonly used as monotherapy due to its efficacy, but has disadvantages of drug interactions, required therapeutic drug monitoring, and dose-related adverse effects, including drowsiness and dizziness $[40,44]$. The drug interaction between phenytoin and dexamethasone is especially concerning. Both drugs induce the metabolism of the other, resulting in increasing dosage requirements of both for seizure and edema control [45]. Therapeutic doses of phenytoin when used concomitantly with dexamethasone have been reported as high as 600 to $1000 \mathrm{mg} /$ day. Other AEDs used as monotherapy in patients with GBM include topiramate, zonisamide, and lamotrigine $[40,44]$.

Seizure Control - implications for the pharmacist: Seizure control in patients with GBM is difficult due to disease progression, worsening edema, and drug interactions [5]. Pharmacists can assist in seizure control and toxicity management through therapeutic drug monitoring, especially in the case of highly protein-bound AEDs such as phenytoin and valproic acid. Dexamethasone is administered periodically to patients with GBM, and it is not uncommon for patients to have multiple dose adjustments to effectively reduce brain edema. Because of the ability of dexamethasone to induce CYP3A4, dose adjustments in AEDs metabolized through this pathway are often warranted, and can be recognized and managed by pharmacists.
Venous thromboembolism: Like many cancers, GBM is associated with an increased risk for venous thromboembolism (VTE) [46-48]. It is estimated that symptomatic VTE occurs in $19 \%$ to $29 \%$ of patients with gliomas. Identified risk factors for VTE in patients with malignant glioma include larger tumor size, leg paresis, operation time $>4$ hours, and use of chemotherapy [46]. A retrospective cohort study of 9489 patients diagnosed with malignant glioma in the 1990s was followed for 2 years [47]. Over half of these patients had GBM. The investigators found that over 6 months, 1 year, and 2 years, the cumulative incidences of VTE in the entire cohort were $6.1 \%, 7.0 \%$, and $7.5 \%$, respectively. Among those who experienced a VTE, 70\% had a deep vein thrombosis and $30 \%$ had a pulmonary embolism. Approximately half of these patients had undergone neurosurgery in the preceding 2 months. Similar to other findings, patients with GBM were at an increased risk for VTE compared to other histologies (HR, 1.7; 95\% CI, 1.3 to 2.3). Patients with $\geq 3$ comorbidities were at a 3.5-fold greater risk for VTE than those without comorbidities (HR, 3.5; 95\% CI, 2.8 to 4.3). Another risk factor was age $\geq 65$ years. The greatest limitation to these findings is that the standard regimen of temozolomide and radiation had not been instituted as a standard of care during the time of this study, so these data do not account for any effects this regimen would have on VTE development.

Data are limited on safety and efficacy of VTE prophylaxis in patients with brain tumors [48]. Because of this and the increased risk for intracranial hemorrhage (ICH), it is recommended that prophylaxis be reserved for surgical and hospitalized patients. Both unfractionated heparin (UFH) and low molecular weight heparin have been studied in this patient population and are effective at VTE reduction. As for the treatment of VTE in patients with brain tumors, most trials on pharmacologic agents have excluded patients with brain tumors. Use of pharmacologic agents is limited by clinicians' concerns for ICH, patient compliance, and drug interactions. While inferior vena cava filters have been used historically, data in the last decade have shown UFH displays superior efficacy and acceptable safety. An initial UFH bolus should be considered carefully, as it is associated with a transient state of overanticoagulation, which can lead to hemorrhagic complications.

Low molecular weight heparin is not ideal for initial treatment because it has a longer half-life and is not as easy to monitor as UFH. Its role in this patient population may be better suited as bridging therapy to long-term treatment with warfarin in a patient who has successfully tolerated UFH. Long-term use of warfarin has shown to be effective and safe for patients with brain tumors. Management of these patients is the same as the general population, but they may require more frequent monitoring.

Venous thromboembolism - implications for the pharmacist: Because patients with GBM are in a persistent hypercoaguable state, pharmacists can play in important role in 


\section{Cancer Therapy \& Oncology International Journal}

counseling patients on the signs and symptoms of VTE, as well as managing maintenance medications of those patients being treated for VTE. Signs and symptoms of bleeding should be discussed as well. In all cases, management of drug interactions should involve a thorough review of pertinent labs, medication and medical history, and future management plans, as well as collaboration with the patient's care team. (Table 8) provides general tips for patient counseling for patients with GBM.

Table 8: Pharmacist counseling points for temozolomide.

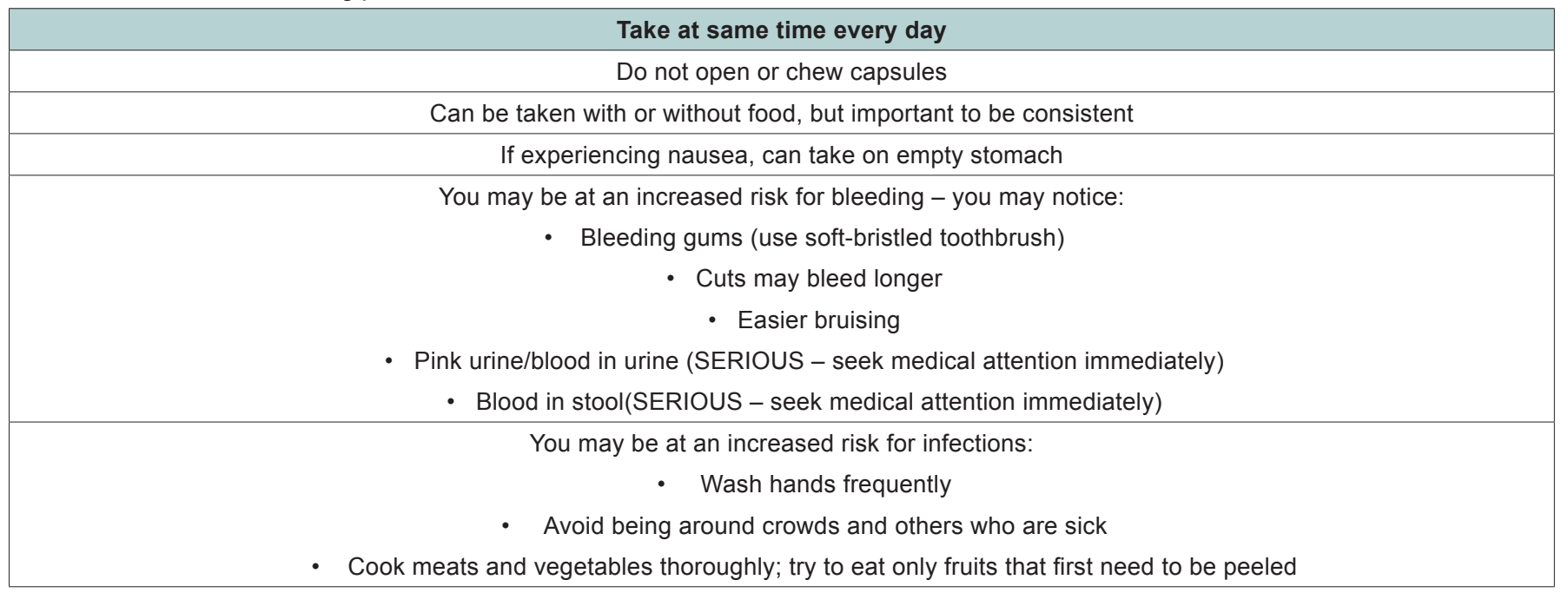

Depression, cognitive impairment, and fatigue: Patients with GBM experience a great emotional (and physical) burden from the time of diagnosis through treatment. Many patients experience mood disturbances, cognitive problems, fatigue, and existential distress throughout the course of their disease [49]. Tumor location has been implicated in mood disturbances, with depression being associated with left-sided and frontal tumors. Depression has been estimated to occur in $15 \%$ to $28 \%$ of patients with GBM, but results from patient selfreporting are often higher. However, there are little data on the use of antidepressants in this patient population. In order to investigate selective serotonin reuptake inhibitors (SSRIs) and their impact on toxicities and survival in patients with GBM, a review was performed on data from 160 patients from 1999 to 2008 [50]. A majority of the patients received temozolomide and radiation, and $21.8 \%$ of patients overall received SSRIs during initial therapy. The most common SSRIs were sertraline and citalopram. No difference in toxicities was observed between patients taking SSRIs and those who were not. Interestingly, 2-year survival in patients taking SSRIs was $31.8 \%$ and $17.4 \%$ in those not taking SSRIs, although this difference was not statistically significant $(\mathrm{P}=0.18)$.

Cognitive impairment and fatigue are not uncommon in patients with GBM [49]. A left-sided tumor can affect verbal fluency and learning, attention, and executive functioning. More progressive, or high-grade tumors, have been associated with rapid decline in cognition, but long-term survivors (over 3 years from diagnosis) may only have moderate cognitive impairment, allowing them to continue activities of daily living $[49,51]$. Fatigue is commonly reported in patients with all grades of GBM, and may be most prominent after radiation. Along with non-pharmacologic behaviors (activity enhancement, cognitive behavioral therapy, etc), psychostimulants such as methylphenidate are options for those who suffer from extreme fatigue [52].

Depression, cognitive impairment, and fatigue implications for the pharmacist: Because of the cognitive decline that many patients with GBM experience, frequent and repeated verbal and written communication with patients and their caregivers is of utmost importance [49]. Pharmacists are in the unique position to empower patients and their caregivers with the information they need to understand and adhere to their treatment plan, and devise solutions for how to implement changes. Pharmacists can help manage treatment-related adverse effects, and aid in the identification and avoidance of drug-drug interactions, which have potential to result in further adverse effects and toxicities.

\section{Conclusion}

Glioblastoma multiforme is the most common form of malignant brain tumors in the adult population. New therapies such as bevacizumab have emerged in the treatment of newly diagnosed GBM and recurrent disease. As such, pharmacists are integral in the management of these patients. There are numerous challenges regarding dispensing, dosing, administration of medication, and patient understanding of disease. It is imperative that pharmacists obtain medication histories at all encounters since patients are commonly taking concomitant therapy for management of sequelae (eg, anticonvulsant therapy) which can result in clinically relevant drug-drug interactions. As patients with GBM often have neurocognitive complications, pharmacists should ensure comprehension of oral medication counseling. 


\section{Cancer Therapy \& Oncology International Journal}

Compounding of TMZ in the community practice setting may be necessary for patients who are unable to take numerous capsules $[53,54]$.

It is important that detailed medication calendars are provided and caregivers are actively involved in the management of these patients. Also, in the community practice setting, laboratory parameters such as ANC and platelet counts should be documented prior to temozolomide dispensing to prevent hematological toxicities. Drug acquisition is often a problem with temozolomide resulting in pharmacists applying for the drug assistant program such as the ACT Program to obtain free product, samples, coupons, and vouchers for patients. In the hospital setting, laboratory values and vitals should be documented when administering bevacizumab to prevent hypertension, impaired wound healing, and proteinuria. Improved knowledge of GBM and its sequelae, and an understanding of patient comprehension issues will greatly assist pharmacists in both institutional and community practice settings in the management of patients with GBM.

\section{References}

1. Preusser M, de Ribaupierre S, Wöhrer A, Erridge SC, Hegi M, et al (2011) Current concepts and management of glioblastoma. Ann Neurol 70(1): 9-21.

2. Adamson C, Kanu 00, Mehta AI, Di C, Lin N, et al. 2009 Glioblastoma multiforme: a review of where we have been and where we are going. Expert Opin Investig Drugs 18(8): 1061-1083.

3. Salacz ME, Watson KR, Schomas DA (2011) Glioblastoma, Part I: current state of affairs. Mo Med 108(3): 187-194.

4. American Brain Tumor Association (2014) Glioblastoma and malignant astrocytoma. 1-20.

5. Shonka NA, Hsu SH, Yung WA, Mahajan A, Prabhu S (2014) Tumors of the central nervous system. In: Hagop M. Kantarjian, Robert A. Wolff, et al. (Eds.), The MD Anderson Manual of Medical Oncology (2 ${ }^{\text {nd }}$ edn), McGraw-Hill, New York, USA.

6. Central Brain Tumor Registry of the United States (2014) CBTRUS statistical report: primary brain and central nervous system tumors diagnosed in the United States in 2004-2008.

7. National Comprehensive Cancer Network (2014) Clinical practice guidelines in oncology: central nervous system cancers.

8. Weller M, Felsberg J, Hartmann C, Berger H, Steinbach JP, et al. (2009) Molecular predictors of progression-free and overall survival in patients with newly diagnosed glioblastoma: A prospective translational study of the German Glioma Network. J ClinOncol 27(34): 5743-5750

9. DeVita VT Jr, Lawrence TS, Rosenberg SA (2008) Cancer Principles \& Practice of Oncology. ( $8^{\text {th }}$ edn), Lippincott Williams and Wilkins, Philadelphia, USA.

10. Merck Sharp and Dohme (2014) Temodar (temozolomide) package insert. Whitehouse Station, New Jersy, USA.

11. Neyns B1, Tosoni A, Hwu WJ, Reardon DA (2010) Dose-dense temozolomide regimens: antitumor activity, toxicity, and immunomodulatory effects. Cancer 116(12): 2868-2877.

12. Stupp R, Mason WP, van den Bent MJ, Weller M, Fisher B, et al. (2005) Radiotherapy plus concomitant and adjuvant temozolomide for glioblastoma. N Engl J Med 352(10): 987-996.
13. Stupp R, Hegi ME, Mason WP, van den Bent MJ, Taphoorn MJ, et al. (2009) Effects of radiotherapy with concomitant and adjuvant temozolomide versus radiotherapy alone on survival in glioblastoma in a randomised phase III study: 5-year analysis of the EORTC-NCIC trial. Lancet Oncol 10(5): 459-466.

14. Perry JR, Rizek P, Cashman R, Morrison M, Morrison T (2008) Temozolomide rechallenge in recurrent malignant glioma by using a continuous temozolomide schedule: the "rescue" approach. Cancer 113(8): 2152-2157.

15. Wick A, Felsberg J, Steinbach JP, Herrlinger U, Platten M, et al. (2007) Efficacy and tolerability of temozolomide in an alternating weekly regimen in patients with recurrent glioma. J ClinOncol 25(22): 33573361.

16. Tolcher AW, Gerson SL, Denis L, Geyer C, Hammond LA, et al. (2003) Marked inactivation of $\mathrm{O}^{6}$-alkylguanine-DNA alkyltransferase activity with protracted temozolomide schedules. Br J Cancer 88(7): 10041011.

17. Mark R. Gilbert, Meihua Wang, Kenneth D. Aldape, Roger Stupp, et al. (2011) RTOG 0525: A randomized phase III trial comparing standard adjuvant temozolomide (TMZ) with a dose-dense (dd) schedule in newly diagnosed glioblastoma (GBM). J ClinOncol

18. National Comprehensive Cancer Network (2014) Clinical practice guidelines in oncology: antiemesis v.2.

19. Villano JL, Letarte N, Yu JM, Abdur S, Bressler LR (2011) Hematologic adverse events associated with temozolomide. Cancer ChemotherPharmacol 69(1): 107-113.

20. National Comprehensive Cancer Network (2014) Prevention and treatment of cancer-related infections v1.

21. ISMP Quarterly Action Agenda. ISMP Medication Safety Alert. April June 2004.

22. John F. Mitchell (2014) Oral dosage forms that should not be crushed. Institute for Safe Medicine Practices.

23. Allen Loyd V Jr (2007) Temozolomide $10 \mathrm{mg} / \mathrm{mL}$ oral liquid. Int J Pharm Compound 11(4): 336.

24. Motomura K, Natsume A, Wakabayashi T (2012) Intravenous administration of temozolomide as a useful alternative over oral treatment with temozolomide capsules in patients with gliomas. J Neurooncol 106 (1): 209-211.

25. Patient assistance program center. Rx Assist website. http://www. rxassist.org.

26. Friedman HS, Prados MD, Wen PY, Mikkelsen T, Schiff D, et al. (2009) Bevacizumab alone and in combination with irinotecan in recurrent glioblastoma. J ClinOncol 27(28): 4733-4740.

27. Genentech (2013) Inc. Avastin (bevacizumab) package inserts. San Francisco, USA.

28. Kreisl TN, Kim L, Moore K, Duic P, Royce C, et al. (2009) Phase II trial of single agent bevacizumab followed by bevacizumab plus irinotecan at tumor progression in recurrent glioblastoma. J ClinOncol 27(5): 740745 .

29. Walter Taal, Hendrika M Oosterkamp, Annemiek M.E. Walenkamp, Laurens Victor Beerepoot, Monique Hanse, et al. (2013) A randomized phase II study of bevacizumab versus bevacizumab plus lomustine versus lomustine single agent in recurrent glioblastoma: the Dutch BELOB study. J Clin Oncol 31.

30. Olivier L Chinot, Wolfgang Wick, Warren Mason, Roger Henriksson, Frank Saran, et al. (2014) Bevacizumab plus radiotherapytemozolomide for newly diagnosed glioblastoma. N Engl J Med 370(8): 709-722. 


\section{Cancer Therapy \& Oncology International Journal}

31. Wong ET, Gautam S, Malchow C, Lun M, Pan E, etal. (2011) Bevacizumab for recurrent glioblastoma multiforme: a meta-analysis. J Natl Compr Canc Netw 9(4): 403-407.

32. Chamberlain MC (2001) Bevacizumab for the treatment of recurrent glioblastoma. Clin Med Insights Oncol 5: 117-129.

33. Vredenburgh JJ, Desjardins A, Herndon JE 2nd, Marcello J, Reardon DA, et al. (2007) Bevacizumab plus irinotecan in recurrent glioblastoma multiforme. J ClinOncol 25(30): 4722-4729.

34. Clinical Pharmacology [database online]. Tampa, FL: Gold Standard, Inc.; 2012.

35. Kaal EC, Vecht CJ (2004) The management of brain edema in brain tumors. Curr Opin Oncol 16(6): 593-600.

36. Davis ME, Stoiber AM (2011) Glioblastoma multiforme: enhancing survival and quality of life. Clin J Oncol Nurs 15(3): 291-297.

37. Vecht CJ, Hovestadt A, Verbiest HB, van Vliet JJ, van Putten WL (1994) Dose-effect relationship of dexamethasone on Karnofsky performance in metastatic brain tumors: a randomized study of doses of 4, 8, and 16 mg per day. Neurology 44(4): 675-680.

38. Glantz MJ, Cole BF, Forsyth PA, Recht LD, Wen PY, et al. (2000) Practice parameter: anticonvulsant prophylaxis in patients with newly diagnosed brain tumors. Report of the Quality Standards Subcommittee of the American Academy of Neurology. Neurology 54(10): 1886-1893.

39. Oberndorfer S, Piribauer M, Marosi C, Lahrmann H, Hitzenberger $\mathrm{P}$, et al. (2005) P450 enzyme inducing and non-enzyme inducing antiepileptics in glioblastoma patients treated with standard chemotherapy. J Neurooncol 72(3): 255-260.

40. Englot DJ, Berger MS, Chang EF, Garcia PA (2012) Characteristics and treatment of seizures in patients with high-grade glioma: a review. Neurosurg Clin N Am 23(2): 227-235.

41. Weller M, Gorlia T, Cairncross JG, van den Bent MJ, Mason W, et al. (2011) Prolonged survival with valproic acid use in the EORTC/NCIC temozolomide trial for glioblastoma. Neurology 77(12): 1156-1164.

42. Wen PY, Schiff D (2011) Valproic acid as the AED of choice for patients with glioblastoma? The jury is out. Neurology 77(12): 114-115.
43. van Breemen MS, Rijsman RM, Taphoorn MJ, Walchenbach R, Zwinkels $\mathrm{H}$, et al. (2009) Efficacy of anti-epileptic drugs in patients with gliomas and seizures. J Neurol 256(9): 1519-1526.

44. Vecht CJ, Van Breemen M (2006) Optimizing therapy of seizures in patients with brain tumors. Neurology 67(4): S10-S13.

45. Ruegg S (2002) Dexamethasone/phenytoin interactions: neurooncological concerns. Swiss Med Wkly 132(29-30): 425-426.

46. Marras LC, Geerts WH, Perry JR (2000) The risk of venous thromboembolism is increased throughout the course of malignant glioma. Cancer 89(3): 640-646.

47. Semrad TJ, O’Donnell R, Wun T, Chew H, Harvey D, et al. (2007) Epidemiology of venous thromboembolism in 9489 patients with malignant glioma. J Neurosurg. 106(4): 601-608.

48. Gerber DE, Grossman SA, Streiff MB (2006) Management of venous thromboembolism in patients with primary and metastatic brain tumors. J ClinOncol 24(8): 1310-1318.

49. Catt S, Chalmers A, Fallowfield L (2008) Psychosocial and supportivecare needs in high-grade glioma. Lancet Oncol 9(9): 884-891.

50. Caudill JS, Brown PD, Cerhan JH, Rummans TA (2011) Selective serotonin reuptake inhibitors, glioblastoma multiforme, and impact on toxicities and overall survival. Am J Clin Oncol 34(4): 385-387.

51. Flechl B, Ackerl M, Sax C, Dieckmann K, Crevenna R, et al. (2012) Neurocognitive and sociodemographic functioning of glioblastoma long-term survivors. J Neurooncol 109(2): 331-339.

52. National Comprehensive Cancer Network (2014) Clinical practice guidelines in oncology: cancer-related fatigue v.1.

53. Wickersham RM (2012) (Ed.), Drug Facts and Comparisons. Wolters Kluwer Health. St. Louis, USA.

54. Norden AD, Bartolomeo J, Tanaka S, Drappatz J, Ciampa AS, et al. (2012) Safety of concurrent bevacizumab therapy and anticoagulation in glioma patients. J Neurooncol 106(1): 121-125.

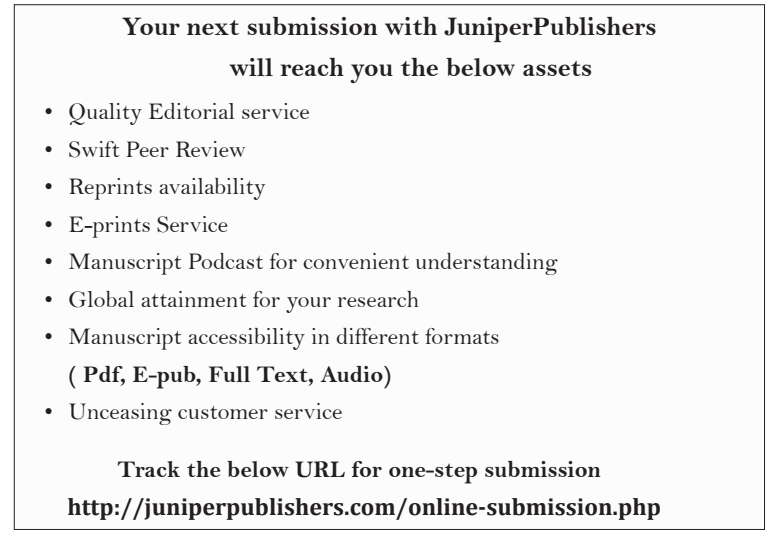

